\title{
THE NABATAEAN TIMING SYSTEM
}

\author{
MAHDI ALZOUBI \\ The Hashemite University, Queen Rania Faculty for Tourism and Heritage \\ P.O. Box 150459, Zarqa 13115, Jordan \\ e-mail: mahdi@hu.edu.jo
}

Archaeological remains yield remarkable information concerning the Nabataeans' timing system; excavations and surveys revealed water clocks, sundials and ground shadow clocks in Nabataean sites, namely Petra and Hegra. Besides, certain Nabataean inscriptions expose a good deal of evidence regarding the Nabataean timing terminology: $y w m$ 'day'; šnt 'year'; yrh 'month'; šch 'hour'; $\check{s} b^{c}$ 'week', lyly' 'night' and zmn 'time' are the most frequently used terms found in the different Nabataean texts. Moreover, the excavations uncovered some archaeological evidence concerning the Nabataean annual calendar. The study adopts a comparative historical and linguistic perspective in investigating the different aspects of time measurement in Nabataean civilisation.

Key words: Nabataean, dating system, calendar, sundial, water clock, time measuring.

\section{Introduction}

Time is of significant social importance; it has been for long a major subject of studies in history, religion, philosophy and science. For example, time measuring has social and personal value in human life, recording public events like the death of a king or rituals. Awareness of time dates back to the early beginnings of human society. Artifacts from the Paleolithic period strongly suggest that first the moon was used for measuring time as early as 6000 years ago.

In subsequent periods, in various ancient world civilisations, a large variety of time measurement devices were invented. The earliest devices and tools used for measuring time were shadow and water clocks.

With the gradual development of human civilisation, there was an urgent need for precise time measuring. For example, in agriculture, it was important to be able to determine the time for planting, sowing and harvesting. The same applies to rituals, 
feasts and other important events, all of which called for more developed time measuring devices to serve daily-life activities and purposes (Wayatt 2001, p. 34).

\section{Nabataean Time Counting Tools}

When the Nabataean people moved from nomadic to settled life, they first established their kingdom, with Petra as the capital city. Thus many aspects of their life, whether social, economic or political, were changed to meet the needs of their new type of settlement as urban people. Influenced by neighbouring cultures, Nabataeans started adopting and developing a new cultural system of their own. As traders and travellers, the Nabataeans worked on transferring some time measuring devices adapted and developed by other earlier settled cultures.

Time measuring, among others, became crucial for the newly emerged Nabataean society. Excavations and archaeological surveys reveal some Nabataean time counting tools which can be grouped as follows:

\section{Sundials}

A sundial is a device that measures time depending on the position of the sun. It measures the local time using the length of the shadow. The earliest examples of the use of sundials come from Egyptian and Babylonian astronomy around 1500 BC. Evidence of the early use of the sundial can also be found in the Old Testament, namely the "dial of Ahaz" is mentioned in Isaiah 38:8 and II Kings 20:8-11.

The ancient Greeks developed many of the principles and forms of sundials that are believed to have been introduced to Greece by Anaximander of Miletus in 560 BC. According to Herodotus, the Greeks' sundials were initially derived from the Babylonian culture; a long time afterwards, Romans adopted the Greek sundials. The first record of a sundial in Rome dates back to 293 BC according to Pliny (1855, t. 7, p. 213).

It seems that the Nabataeans borrowed the sundial time-measuring technique from the Romans. The wide connections of the Roman Empire with the Nabataean traders opened doors to greater world connections, fostering an impressive borrowing of diverse technical and cultural elements.

Nabateans used sundials to calculate day time. A sundial has a surface with hour lines and a stick or gnomon which casts a shadow on the surface as the sun proceeds in its daily course. The pattern of a sundial was found in the Nabatean main sites; one of these examples was found near Hegra during the construction of the Hijâz Railway (see Figure 1). This is made of local sandstone, and it is a typical Roman-Hellenistic dial design (Healey 1989, pp. 331-336). A linear inscription is carved in the bottom of the sundial, and it reads as: $m n \check{s} b r$ ntn $\check{s} l m$ (" $m n \check{s}$ 's son of $n t n$, peace"), and it is dated to the 1 st century AD. This inscription seems to indicate the owner or the commissioner of the dial rather than its actual designer (Healey 1989, pp. 333-334). 


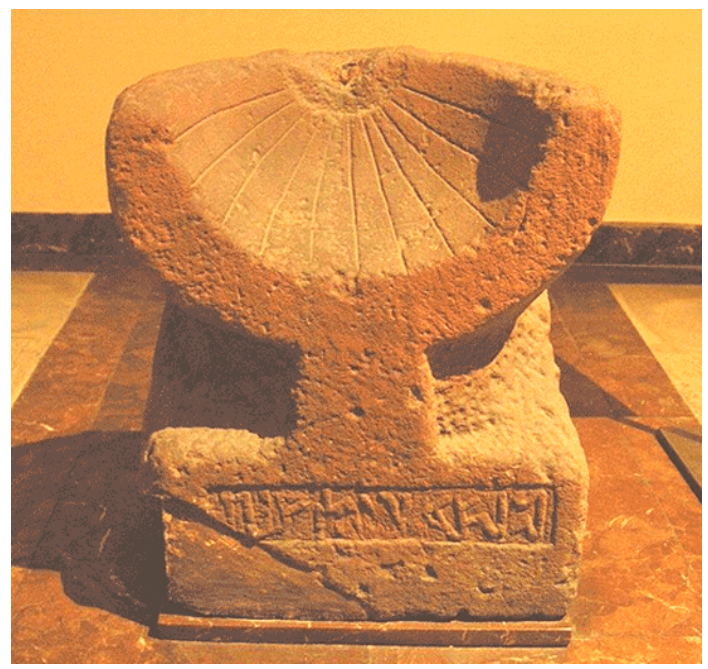

Figure 1. Nabataean sundial (Healey 1989, p. 332)

The time-keeping surface of this sundial is divided into segments marking the hours of the day. In addition to the hour-lines there is a single day-curve parallel to the front edge (Healey 1989, pp. 331-336).

Another amazing example was found at Dumayr near Damascus; a sundial carved on the top horizontal surface of an altar. This sundial is of hemispherical shape with three day-curves. Starcky and Healey assume that this sundial had been added to the altar at a later date (Healey 1989, p. 335).

Obelisks, connected with the sun and designed as a representation of the sun's rays, serve as a tool of time measuring depending on the shadow's movement. An obelisk seems to have been used as a form of sundials (see Figure 2). In addition to its

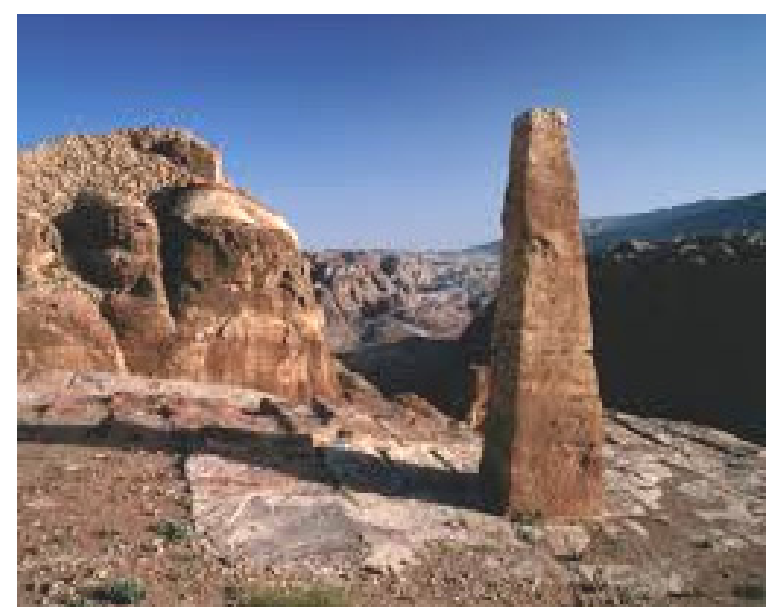

Figure 2. Obelisk from Petra (Belmonte-García-Polcaro 2013, p. 488) 
religious and commemorative functions, it was a very useful way to control time within the framework of a lunisolar calendar (Belmonte-García-Polcaro 2013, pp. 487501). Patterns of obelisks standing on mountain tops have been found in Petra and Hegra. The movement of shadow enables one to read the hours all year round, where a tiled floor is used to calculate the hours (al-Nawafleh 2012, p. 20).

In addition to their function of calculating the hours of the day, dials could have also been used to mark the times of worship.

\section{Water Clocks}

The use of water clocks dates back to the ancient Egyptian and Mesopotamian civilisations around $1500 \mathrm{BC}$. Greeks also used this time calculation technique around the 3rd century BC, and they called it Clepsydra (water thief). Archaeological evidence confirms that ancient Nabataeans also used this time measuring tool; it was very beneficial during the night time and cloudy days when sundials were inefficient. A water clock system consists of a sink filled with water which runs through a connected pipe to a square tank, and the time is measured by the volume or weight of the water discharged rather than the difference in level.

\section{The Ground Shadow Clock}

Although not certain, only one example of the Nabataean ground shadow clock was found at Petra. Al-Nawafleh $(2012$, p. 23) claims that the oblong table in the paved ground of the High Place at Petra is a ruin of a Ground Shadow Clock, and the time was measured using a ground shadow marker which has possibly been damaged due to natural or human causes of decay (Figure 3).

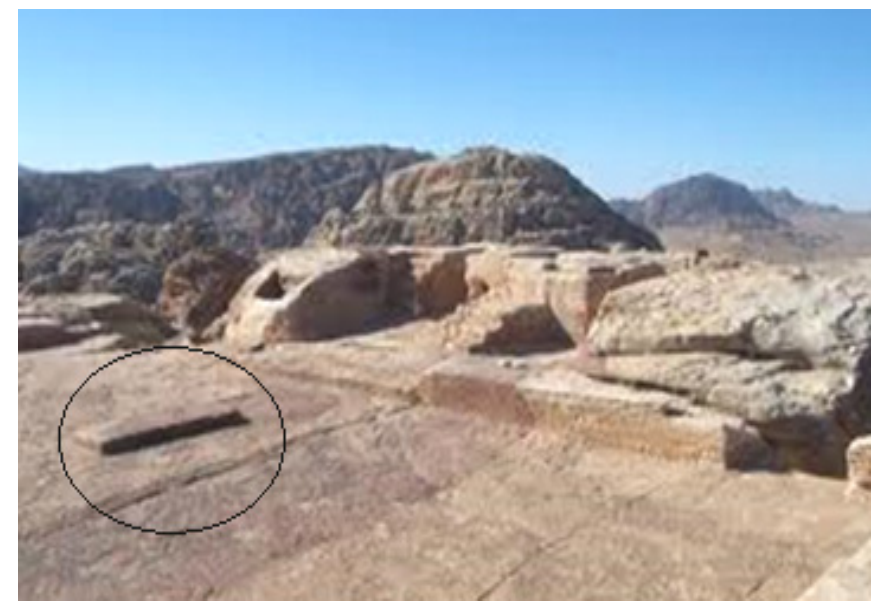

Figure 3. The Ground Shadow Clock (al-Nawafleh 2012, p. 23) 


\section{The Nabataean Calendar}

While archaeological artifacts reveal few but interesting indications concerning the Nabataean Calendar, Nabataean written documents do not provide us with a clear image. A zodiac relief found at Khirbat al-Tannur and another zodiacal pottery lamp from Petra represent (see Figures 4 and 5) our main direct archaeological resources concerning the Nabataean Calendar (Glueck 1952, pp. 5-10).

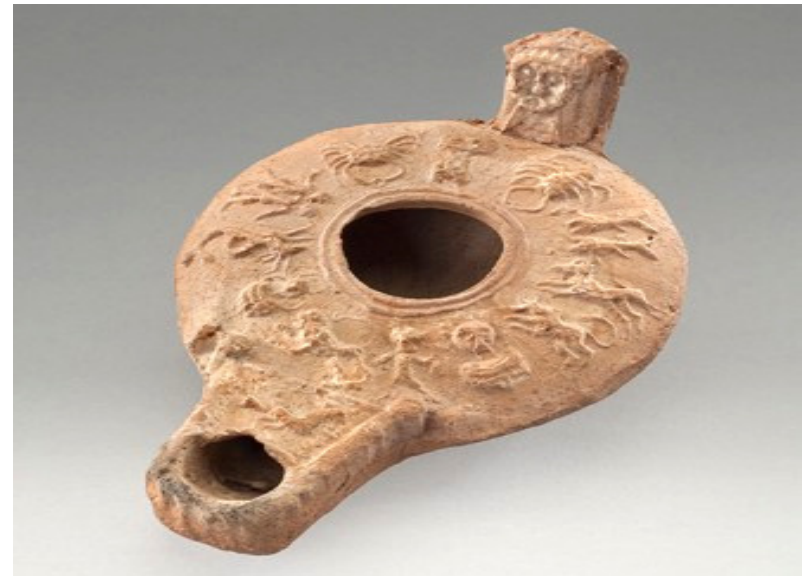

Figure 4. Lamp with the signs of the zodiac from Petra, Jordan.

Clay, Temple of the Winged Lions, 1st Century AD (Amman Archaeological Museum)

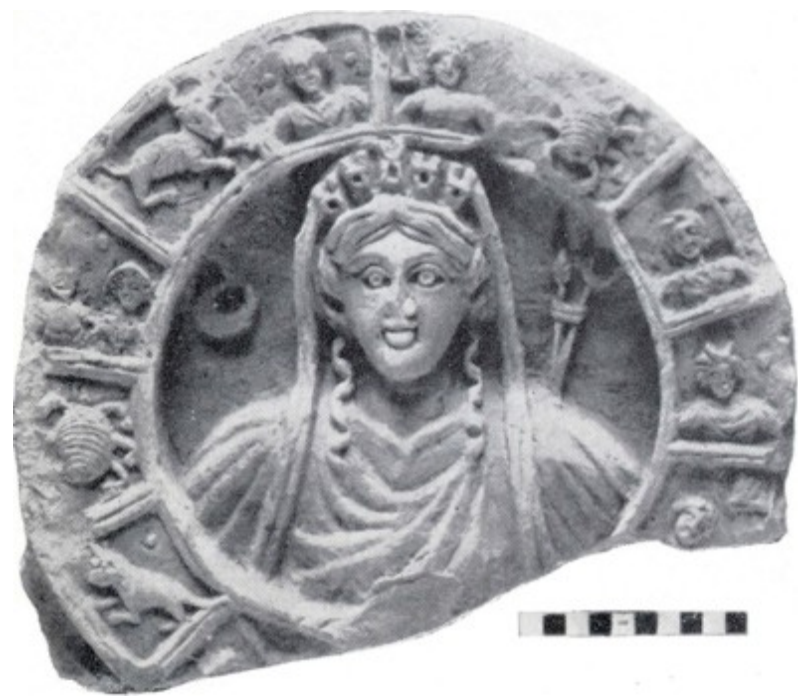

Figure 5. Zodiac Panel from Khirbet Al-Tannur (al-Nawafleh 2012, p. 51) 
The Nabataean zodiac relief of Khirbat al-Tannur contributed to our knowledge regarding the Nabataean year division. Zodiac was like a calendar expressing the belief of a cyclical passage of time. This Nabataean zodiacal panel is divided into clockwise and counter clockwise halves. N. Glueck (1965, p. 7) suggests that these mark two new-year divisions: a natural new year beginning with spring and a civic new year beginning in autumn (al-Salameen-Falahat 2009, p. 183).

Like the Roman zodiac version, the Nabataean one also begins with Aries and is followed by (2) Taurus, (3) Gemini, (4) Cancer, (5) Leo, and (6) Virgo. But the space of the seventh month is occupied by Pisces - the twelfth month in the Roman calendar - instead of Libra which appears at the top beside Aries.

The second item, which represented the Nabataean zodiac known in Nabataean iconography, comes from Petra: it is a unique zodiacal pottery lamp uncovered at the "Temple of the Winged Lions". It displays the signs of the zodiac running clockwise round the filler hole. It begins with a sign for Scorpio, the regular order of zodiac representations was not followed (Hammond 2002, pp. 165-168).

\section{The Nabataean Dating System}

The Nabataean dating system was based upon the regnal years of the Nabataean kings. This was the single method used to count the years across the Nabataean kingdom until its annexation to the Roman Empire, when it was transformed into Provincia Arabia. As the Roman administration abolished the Nabataean sovereignty, the Nabataean timing system was replaced by the provincial era to calculate years.

Before the foundation of the Roman province in $106 \mathrm{AD}$, documents and inscriptions were dated with the Babylonian month names. The Nabataean Kingdom had retained the lunar Babylonian Calendar of the Seleucid period, while texts and inscriptions from $106 \mathrm{AD}$ onward were dated according to the Provincia Arabia system (Stern 2012, p. 291).

The following table shows the month names used in different Nabataean documents published so far:

\begin{tabular}{|l|l|l|l|}
\hline Babylonian & Heb./-Aramaic & Nabataean & Approximate Julian equivalent \\
\hline Nisanu & Nisan & nysn & March/April \\
\hline Aiaru & Iyyar & 'yr & April/May \\
\hline Simanu & Sivan & sywn & May/June \\
\hline Duzu & Tammuz & tmwz & June/July \\
\hline Abu & Ab & 'b & July/August \\
\hline Ululu & Elul & 'lwl & August/September \\
\hline Thashritu & Tishri & - & September/October \\
\hline Arashamnu & Marheshvan & - & October/November \\
\hline Kislimu & Kislev & kslw & November/December \\
\hline Tebetu & Tebet & tbt & December/January \\
\hline Sha-batu & She-bat & šbt & January/February \\
\hline Addaru & Adar & 'dr & February/March \\
\hline
\end{tabular}


In most of the Nabataean dated documents the dating clause consists of the following elements (we may find some or all of these elements in the same inscription): preposition $b+d a y+$ month + year + the king's name (Abdelaziz 2005, p. 193).

Examples of the Provincia Arabia new dating system also occurred in Nabataean texts dated to the period subsequent to the power decline of the Nabataean Kingdom; for example, a tomb inscription from Hegra (JS 17) dates to the year 162 of the Provincia Arabia. Another example comes from the Dead Sea Nabataean Papyri (Yadin 1971, pp. 230-232), dated to the years of Caesar Trajanus Hadrianus.

\section{Nabataean Time Terminology}

Nabataean texts provide us with a considerable number of time terminology, these are as follows:

$\boldsymbol{y} \boldsymbol{w m}$ : is a common Semitic noun meaning 'day'. It occurs in different forms in Nabataean inscriptions: $y m$ : sing, abs. (CIS Vol. II, No. 219); ywm: sing, abs. (CIS Vol. II, No. 211); ywm': sing. emph. (JS 38; Yardeni 2000, p. 862, line 22 ); ymm': plur. emph. (JS 2) and ywmwhy: plur.+ suff. 3 p.s.m (CIS Vol. II, No. 224). - This noun is frequently used in the dating clauses in Nabataean funerary inscriptions and in the sales contracts of palm trees from the Dead Sea region.

šnt: is a common Semitic noun meaning 'year'. It occurs in Nabataean in different forms: $\check{s} n t$ : sing, abs. i.e. CIS Vol. II, No. 213, line 8: by[r]h thbt šnt 45 lhrtt mlk $n b t w$ "in the month of Tebet, the year 45 of Hartat, king of the Nabateans". šnt': sing. emph. i.e.: 'kry lšnt'kwt bh s'yn 'šrh (Yadin et al. 2002, p. 280, line 37) "the share of our lord, the leasing (tax) for a year, as well, in its amount of se'ah, ten”. - šny: plur. abs. i.e. CIS Vol. II, No. 196, line 6: ' l šny hrtt 'mlk nbtww rḥm ${ }^{c} m h$ "during the years of Haretat, King of the Nabataeans, lover of his people". - šnyn plur. abs. i.e.: CIS Vol. II, No. 196: šltwnhm dy šlțw zmnyn try šnyn tltyn wšt "their rule which they exercised for two periods for thirty-six years".

yrh: is a noun (s.m.) meaning 'month'; this is the equivalent of the Akkadian urhu larhu meaning 'month' (al-Theeb 2000, p. 122). This noun also occurs in Ph., Pun., Heb., OffAr. JAr., Palm. and in Hatra (Hoftijzer-Jongeling 1995, pp. 469-470). This noun occurs only in the dating clause in different Nabataean texts.

$\breve{s}^{c} \boldsymbol{h}$ : a noun (s.f.) meaning 'hour'. It occurs in the Nabataean papyri from Nahal Hever, it is also noted in one Palmyrian text as s. emph. $s^{c} t$ ' 'hour, time' (HoftijzerJongeling 1995, p. 1178). We can compare it with Arabic ساعه s $\bar{a}^{c}$ ah meaning 'hour'. Dy bglgl'dy bm[hw]z c gltyn 'l šqy' w'ny myh plqwt šch hhdh bywm hd. "which is in Galgala', which is in Ma[ho]z ${ }^{c}$ Eglatin, including irrigation ditches and assigned watering periods; half an hour on the first day of the week" (Yadin et al. 2002, p. 208, No. 3, lines 24-25).

šb': is a noun (s.m.) meaning 'week' noted only in Nabataean papyri from the Dead Sea Region. It occurs as $\check{s} b$ ' and $\breve{s} b h$ where the determinant is indicated once by suffix aleph and another by he'. The interchange between aleph and he' 
in the Nabataean text from Nahal Hever, as determinant suffix even in the same word, depends on the scribe's degree of adherence to the traditional spelling (Yadin et al. 2002, p. 20).

lyly: is a noun (s.m.) meaning 'night'. It occurred only in one Nabataean funeral text from Hegra as part of a divine title; (JS I 2): $p y l^{c} n$ prš lyly' mn ymm' mn dy ynpq $y$ th $l^{c} l m$. "And may who separates night from day whoever removes them forever" (Healey 1993, p. 83).

$\boldsymbol{z m n}$ : is a noun (s.m.) referring in Nabatean to 'date, fixed time or period' (Healey 1993, p. 190). It occurs in Nabatean as singular zmn (CIS Vol. II, No. 204) and as plural zmnyn (CIS Vol. II, No. 196). This noun also occurs in Aramaic, Hebrew and Arabic. Mn zmn štr mwhbt' dy bydh "from the date of the deed gift which is in her hand" (CIS Vol. II, No. 204).

\section{Conclusion}

Archaeological remains form different Nabataean archaeological sites reveal the time calculation for the Nabataean daily life activities. Time measurement tools, sundials, water clocks and ground shadow clocks were widespread across the main Nabatean cities like Petra and Hegra. Nabataean inscriptions expose a good deal of timing terminology; $y w m$ 'day'; šnt 'year'; yrh 'month'; $\check{s} h$ 'hour'; šb 'c 'week', lyly' 'night' and zmn 'time' occurring in different Nabataean texts, mainly in funerary and legal ones.

Zodiacal pottery lamp and panel from Petra and Khirbet Al-Tannūr reveal important information concerning the Nabatean calendar.

Nabataeans, similarly to other ancient Near Eastern neighbouring civilisations, heavily depended on time measurement tools used for calculating the time for agricultural activities, rituals and festivals. We may even say that the main purpose of calendar use was for dating events.

Nabataean timing measurement techniques show great Roman influence on Nabataean civilisation, namely Nabataean zodiacal items are very close to the Roman zodiac version, but the seventh month's space is occupied by Pisces - the twelfth one on the Roman calendar - instead of Libra which appears at the top beside Aries.

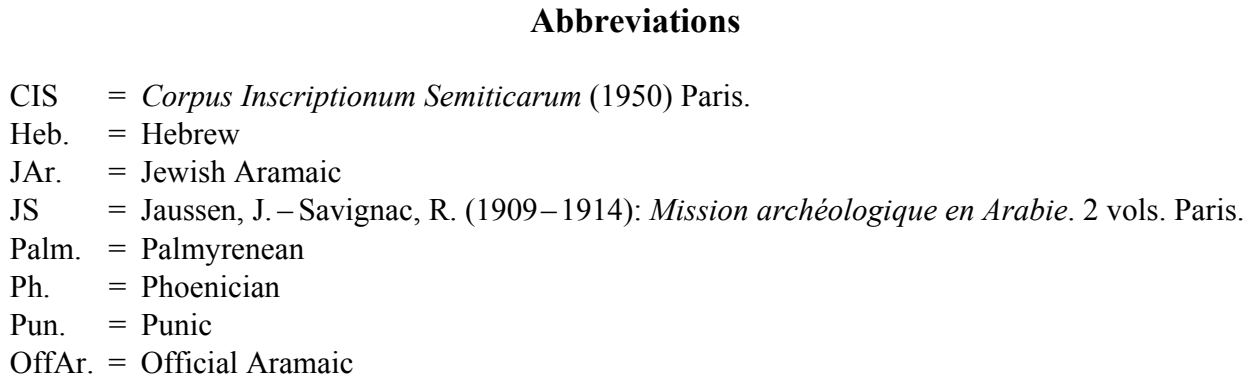




\section{Bibliography}

Abdelaziz, M. (2005): Notes on the Nabataean Legal System. Journal of Dirasat Vol. 32, No. 1, pp. $189-199$.

Belmonte, J. - García, A. - Polcaro, A. (2013): Light and Shadows over Petra: Astronomy and Landscape in Nabataean Lands. Nexus Network Journal Vol. 15, No. 3, pp. 487-501.

Glueck, N. (1952): The Zodiac of Khirbet et-Tannûr. Bulletin of the American Schools of Oriental Research 126, pp. 5-10.

Glueck, N. (1965): The Story of the Nabataeans. Deities and Dolphins. New York, Farrar Straus \& Giroux.

Hammond, Ph. C. (2002): A Note on a Zodiac Lamp from Petra. Palestine Exploration Quarterly Vol. 134, No. 2, pp. 165-168.

Healey, J. (1989): A Nabataean Sundial from Meda'in Salih. Syria 66, pp. 331-336.

Healey, J. (1993): The Nabataean Tomb Inscriptions of Mada'in Salih. Oxford, Oxford University Press on behalf of the University of Manchester.

Hoftijzer, J. - Jongeling, K. (1995): Dictionary of the North-West Semitic Inscriptions. Leiden, Brill. al-Nawafleh, M. (2012): Petraeology, Site Story. Amman, Arapilla for Logistic Services.

Pliny the Elder (1855): The Natural History. London, John Bostock, Henry Thomas Riley.

al-Salameen, Z. - Falahat, H. (2009): Religious Practices and Beliefs in Wadi Mousa between the Late 19th and Early 20th Centuries. Jordan Journal of History and Archaeology Vol. 3, No. 3, pp. 175-204.

Stern, S. (2012): Calendars in Antiquity: Empires, States, and Societies. Oxford, Oxford University Press.

al-Theeb, S. (2000): The Nabataean Dictionary. Rhyadh, King Fahad Library.

Wayatt, N. (2001): Space and Time in the Religious Life of the Near East. England, Sheffield Academic Press.

Yadin, Y. (1971): Bar-Kokhba. The Rediscovery of the Legendary Hero of the Last Jewish Revolt Against Rome. Jerusalem, Littlehampton Book Services Ltd.

Yadin, Y. et al. (2002): Textbook of Aramaic, Hebrew and Nabataean Documentary Texts from the Judean Desert and Related Material (Hebrew). Jerusalem, The Hebrew University, The BenZion Dinur Center for Research in Jewish History.

Yardeni, A. (2000): Textbook of Aramaic, Hebrew and Nabataean - Documentary Texts from the Judean Desert. Jerusalem, The Hebrew University, The Ben-Zion Dinur Center for Research in Jewish History. 